\title{
X-linked neurodegenerative syndrome, Hamel type
}

INSERM

\section{Source}

INSERM. (1999). Orphanet: an online rare disease and orphan drug data base. $\underline{X-l i n k e d}$ neurodegenerative syndrome, Hamel type. ORPHA:85336

An X-linked syndromic intellectual disability characterized by a few months of normal development, followed by progressive neurodegenerative course with gradual loss of vision, development of spastic tetraplegia, convulsions, microcephaly, failure to thrive, and early death. 